\section{Authors' Disclosures of Potential Conflicts of Interest}

No potential conflicts of interest relevant to this article were reported.

\section{REFERENCES}

1. Platzbecker U. Treatment of MDS. Blood 2019;133:1096-107.

2. Santini V, Prebet T, Fenaux P, et al. Minimizing risk of hypomethylating agent failure in patients with higher-risk MDS and practical management recommendations. Leuk Res 2014;38: 1381-91.

3. Voso MT, Niscola P, Piciocchi A, et al. Standard dose and prolonged administration of azacitidine are associated with improved efficacy in a real-world group of patients with myelodysplastic syndrome or low blast count acute myeloid leukemia. Eur J Haematol 2016;96:344-51

4. Tendas A, Lissia MF, Piccioni D, et al. Obstacles to adherence to azacitidine administration schedule in outpatient myelodysplastic syndrome and related disorders. Support Care Cancer 2015;23:303-5

5. Santini V. How I treat MDS after hypomethylating agent failure. Blood 2019;133:521-9.

6. Niscola P, Tendas A, Cupelli L, et al. Dismal outcome of acute myeloid leukemia secondary to myelodysplastic syndrome and chronic myelomonocytic leukemia after azacitidine failure in a daily-life setting. Acta Haematol 2015;133:64-6.

7. Greenberg P, Cox C, LeBeau MM, et al. International scoring system for evaluating prognosis in myelodysplastic syndromes. Blood 1997;89:2079-88.

8. Cheson BD, Bennett JM, Kopecky KJ, et al. Revised recommendations of the International Working Group for Diagnosis, standardization of response criteria, treatment outcomes, and reporting standards for therapeutic trials in acute myeloid leukemia. J Clin Oncol 2003;21:4642-9.

9. Niscola P, Neri B, Catalano G, et al. Decitabine as salvage therapy for primary induction failure of acute myeloid leukemia. Acta Oncol 2017;56:1120-1.

10. Abruzzese E, Trawinska MM, Neri B, et al. Successful decitabine treatment in unfit, elderly patients with acute myeloid leukemia following chronic myeloproliferative neoplasm. Acta Haematol 2018;140:231-3.

11. Varaldo R, Raiola AM, Di Grazia C, et al. Haploidentical bone marrow transplantation in patients with advanced myelodysplastic syndrome. Am J Hematol 2017;92:E117-9.

12. Duong VH, Bhatnagar B, Zandberg DP, et al. Lack of objective response of myelodysplastic syndromes and acute myeloid leukemia to decitabine after failure of azacitidine. Leuk Lymphoma 2015;56:1718-22.
Differential impact of anti-thymocyte globulin dosing by disease risk index in alternative donor peripheral blood stem cell transplantation in patients with acute leukemia or myelodysplastic syndrome after reduced intensity conditioning

TO THE EDITOR: Chronic graft-versus-host disease (GVHD), one of the major hurdles in the way of successful hematopoietic cell transplantation (HCT), has increased in incidence with the widespread use of peripheral blood (PB) grafts and alternative donors, along with an increased number of older transplant recipients [1]. Although anti-thymocyte globulin (ATG) plays a protective role against GVHD across various transplant settings, including alternative donor PB HCT with reduced intensity conditioning (RIC), its optimal dosing in a specific transplant platform remains largely unknown $[2,3]$.

We hypothesized that the impact of different ATG doses can depend on the disease risk index (DRI). The present study aimed to explore this hypothesis by comparing transplant outcomes between total ATG doses of $6 \mathrm{mg} / \mathrm{kg}$ and $9 \mathrm{mg} / \mathrm{kg}$ in a homogenous population stratified by DRI. These patients received PB grafts from alternative donors after a specified RIC regimen for acute leukemia or myelodysplastic syndrome (MDS).

We retrospectively identified 130 eligible patients who had undergone their first HCT between February 2008 and March 2017 at Seoul National University Hospital (SNUH) and Seoul National University Bundang Hospital (SNUBH). The donors included 10/10 human leukocyte antigen (HLA) allele-matched unrelated donors (MUDs), $7 / 10$ or $8-9 / 10$ partially matched unrelated donors (PUDs), and 3-4/6 or 3-7/8 or $6 / 10$ haploidentical familial donors (HIDs), while the graft source consisted of PB stem cells only. Conditioning included the administration of intravenous busulfan at a dose of $3.2 \mathrm{mg} / \mathrm{kg}$ on day D-7 and D-6, fludarabine at 30 $\mathrm{mg} / \mathrm{m}^{2}$ from $\mathrm{D}-7$ to $\mathrm{D}-2$, and rabbit ATG (Thymoglobulin) at 2.0 or $3.0 \mathrm{mg} / \mathrm{kg}$ from D-3 to D-1. Cyclosporine A or tacrolimus were additionally used with or without methotrexate. The study protocol was reviewed and approved by the Institutional Review Boards of SNUH and SNUBH.

Baseline characteristics of included patients are summarized in Supplementary Table 1. The median follow-up period for the total population was 35.00 months [95\% confidence interval (CI), 30.34-39.66]. In the total population, the GVHD-free, relapse-free survival (GRFS), disease-free survival (DFS), and overall survival (OS) tended to be longer when using the $6 \mathrm{mg} / \mathrm{kg}$ dose than when $9 \mathrm{mg} / \mathrm{kg}$ was used, but without statistical significance (Fig. 1A-C). In 99 patients with low/intermediate DRI, those in the $6 \mathrm{mg} / \mathrm{kg}$ 
group had significantly higher DFS and OS than those in the $9 \mathrm{mg} / \mathrm{kg}$ group, while their GRFS was similar. The estimates of 2-year GRFS, DFS, and OS rates were 31\% (95\% CI, 23-40) vs. $25 \%$ (95\% CI, 19-30; $P=0.133$; Fig. 1D), $65 \%$ (95\% CI, 57-74) vs. $43 \%$ (95\% CI, 37-49; $P=0.017$; Fig. $1 \mathrm{E})$, and $73 \%$ (95\% CI, $65-81$ ) vs. $53 \%$ (95\% CI, $46-59$; $P=0.018$; Fig. 1F), for the $6 \mathrm{mg} / \mathrm{kg}$ group vs. $9 \mathrm{mg} / \mathrm{kg}$ group, respectively. In contrast, for 31 patients with a high or very high DRI the GRFS, DFS, and OS did not differ significantly between the different ATG doses. The estimates of 2-year GRFS, DFS, and OS rates were 20\% (95\% CI, 7-33) vs. 29\% (95\% CI, 19-39; $P=0.999$; Fig. $1 \mathrm{G}), 20 \%$ (95\% CI, 7-33) vs. $38 \%$ (95\% CI, 28-49; $P=0.386$; Fig. $1 \mathrm{H})$, and $30 \%$ (95\% CI, $16-45$ ) vs. $38 \%$ (95\% CI, 28-49; $P=0.855$; Fig. 1I), for the $6 \mathrm{mg} / \mathrm{kg}$ group vs. $9 \mathrm{mg} / \mathrm{kg}$ group, respectively.

Grade III-IV acute GVHD at day 100 and chronic GVHD

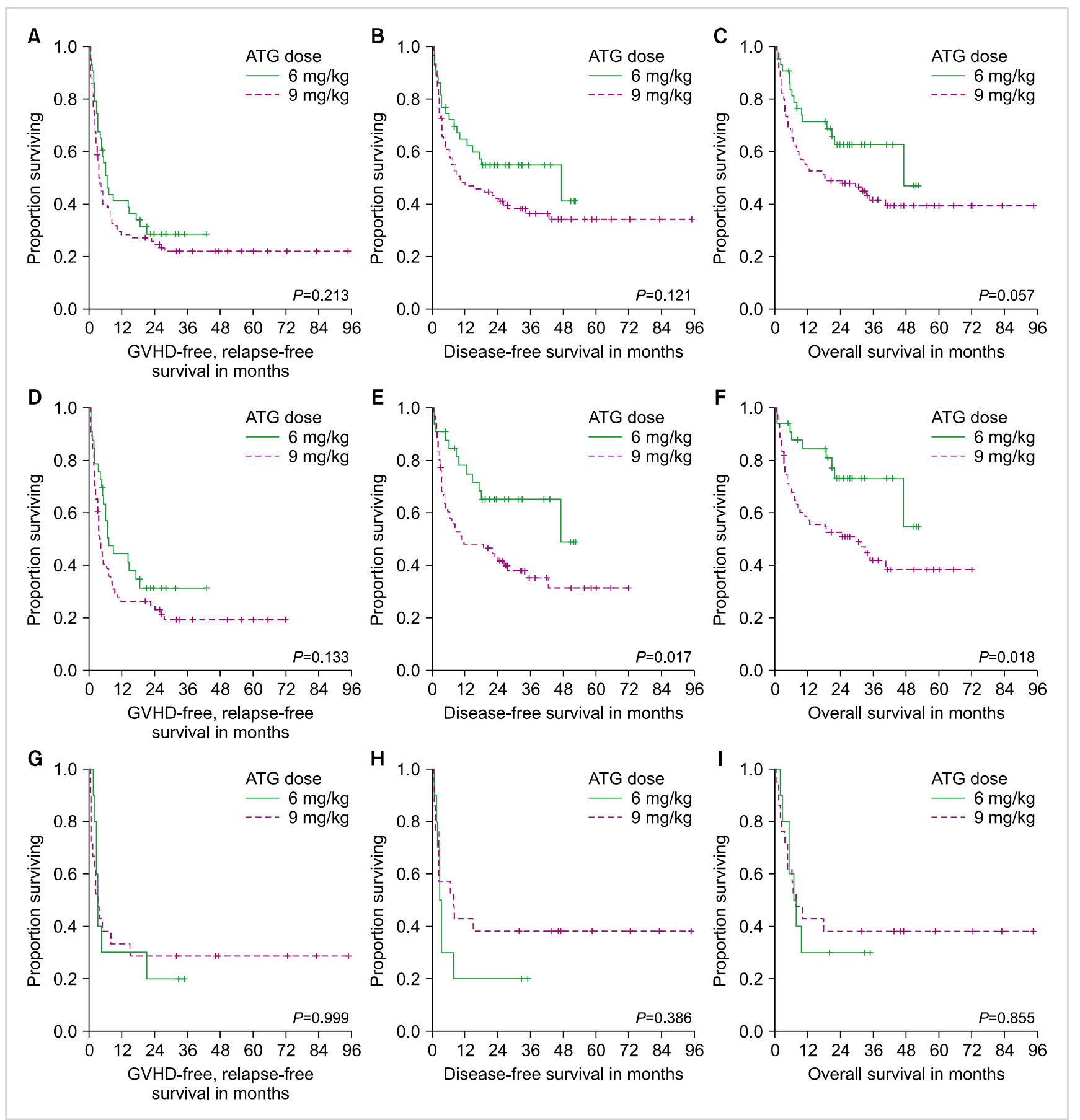

Fig. 1. Graft-versus-host disease (GVHD)-free, relapse-free survival (GRFS), disease-free survival (DFS), and overall survival (OS) by total dose of anti-thymocyte globulin (ATG) in the overall population (A-C), in subgroups with low/intermediate disease risk indices (DRI; D-F), and in subgroups with high/very high DRI (G-I). 
Table 1. Cox regression analyses for overall survival.

\begin{tabular}{|c|c|c|c|c|c|}
\hline Parameters & $\mathrm{N}$ & $\begin{array}{c}\text { Univariable } \\
\text { hazard ratio }(95 \% \mathrm{Cl})\end{array}$ & $P$ & $\begin{array}{c}\text { Multivariable } \\
\text { hazard ratio }(95 \% \mathrm{Cl})\end{array}$ & $P$ \\
\hline Patient age & & $1.00(0.98-1.02)$ & 0.979 & & \\
\hline \multicolumn{6}{|l|}{ Patient sex } \\
\hline Female & 62 & 1 & & 1 & \\
\hline Male & 68 & $1.92(1.16-3.16)$ & 0.011 & $1.85(1.11-3.09)$ & 0.019 \\
\hline \multicolumn{6}{|c|}{ Female-to-male combination } \\
\hline No & 109 & 1 & & & \\
\hline Yes & 21 & $1.54(0.84-2.83)$ & 0.162 & & \\
\hline \multicolumn{6}{|l|}{ Diagnosis } \\
\hline AML & 78 & 1 & & & \\
\hline ALL & 19 & $0.89(0.43-1.83)$ & 0.747 & & \\
\hline MDS & 33 & $1.17(0.67-2.05)$ & 0.589 & & \\
\hline $\mathrm{HCT}-\mathrm{Cl}$ scores & & $1.33(1.06-1.67)$ & 0.012 & $1.36(1.06-1.76)$ & 0.018 \\
\hline \multicolumn{6}{|l|}{ Disease risk index } \\
\hline Low/intermediate & 99 & 1 & & 1 & \\
\hline High/very high & 31 & $1.65(0.98-2.80)$ & 0.062 & $4.14(1.52-11.26)$ & 0.005 \\
\hline \multicolumn{6}{|l|}{ Timing of transplant } \\
\hline 2013-2018 & 120 & 1 & & & \\
\hline 2008-2012 & 10 & $1.11(0.48-2.57)$ & 0.814 & & \\
\hline \multicolumn{6}{|l|}{ Donor type } \\
\hline MUD & 55 & 1 & & 1 & \\
\hline HID & 31 & $1.22(0.69-2.16)$ & 0.492 & $1.29(0.71-2.33)$ & 0.399 \\
\hline PUD & 44 & $1.30(0.68-2.48)$ & 0.430 & $0.87(0.43-1.75)$ & 0.687 \\
\hline $\mathrm{CD}_{3} 4^{+}$cells $\left(\times 10^{6}\right) / \mathrm{kg}$ & & $0.91(0.82-1.01)$ & 0.084 & & \\
\hline \multicolumn{6}{|l|}{ ATG total dose } \\
\hline $6 \mathrm{mg} / \mathrm{kg}$ & 43 & 1 & & 1 & \\
\hline $9 \mathrm{mg} / \mathrm{kg}$ & 87 & $1.72(0.98-3.02)$ & 0.060 & $2.56(1.19-5.51)$ & 0.016 \\
\hline ATG total dose $\times$ diseas & & & & $0.26(0.08-0.85)$ & 0.026 \\
\hline \multicolumn{6}{|l|}{ Calcineurin inhibitor use } \\
\hline Cyclosporin A & 68 & 1 & & & \\
\hline Tacrolimus & 52 & $1.00(0.60-1.68)$ & 0.998 & & \\
\hline \multicolumn{6}{|l|}{ Methotrexate use } \\
\hline Yes & 79 & 1 & & & \\
\hline No & 51 & $0.93(0.57-1.53)$ & 0.782 & & \\
\hline
\end{tabular}

${ }^{a)}$ Interaction between ATG total dose and disease risk index.

Abbreviations: ALL, acute lymphoblastic leukemia; AML, acute myeloid leukemia; ATG, antithymocyte globulin; CD34+, cluster of differentiation 34-positive; Cl, confidence interval; $\mathrm{HCT}$-Cl, hematopoietic cell transplantation comorbidity index; HID, haploidentical familial donors; MDS, myelodysplastic syndrome; MUD, matched unrelated donors; OS, overall survival; PUD, partially-matched unrelated donors.

requiring systemic therapy after 2 years of HCT were more frequently noted in the ATG $6 \mathrm{mg} / \mathrm{kg}$ group than in the $9 \mathrm{mg} / \mathrm{kg}$ group, with a cumulative incidence of $23 \%$ vs. $16 \%(P=0.023)$ and $41 \%$ vs. $21 \%(P=0.025)$, respectively. The cumulative incidence estimates of relapse and non-relapse mortality at a 2-year time point were numerically lower when an ATG dose of $6 \mathrm{mg} / \mathrm{kg}$ was used than when $9 \mathrm{mg} / \mathrm{kg}$ was used, with the cumulative incidence being $17 \%$ vs. $24 \%(P=0.517)$ and $29 \%$ vs. $34 \%(P=0.311)$, respectively, albeit without statistical significance (Supplementary Table 2).

Subsequent multivariable analyses showed that patient sex (male), a higher HCT-comorbidity index (HCT-CI), the $9 \mathrm{mg} / \mathrm{kg}$ ATG dose, and high or very high DRI were independently associated with a worse survival, with hazard ratios (HRs) of 1.85 (95\% CI, 1.11-3.09; $P=0.019), 1.36$ (95\% CI, 1.06-1.76; $P=0.018$ ), 4.14 (95\% CI, 1.52-11.26; $P=0.005$ ), and 2.56 (95\% CI, 1.19-5.51; $P=0.016$ ), respectively, while donor type did not harbor this association. Additionally, the interaction between ATG dose and DRI was a significant predictor of OS, with a HR of 0.26 (95\% CI, 0.08-0.85; $P=0.026$; Table 1).

Our findings are consistent with those of previous studies. Remberger et al. reported a lower incidence of GVHD and a higher incidence of relapse with an ATG dose of $8 \mathrm{mg} / \mathrm{kg}$ compared to $6 \mathrm{mg} / \mathrm{kg}$ in RIC HCT from a PB or bone marrow (BM) graft of MUDs, in accordance with our study (Supplementary Table 2) [4]. Chang et al. [5] conducted a prospective randomized trial comparing ATG doses of $6 \mathrm{mg} / \mathrm{kg}$ and $10 \mathrm{mg} / \mathrm{kg}$ in HCT from both PB and BM grafts 
from HIDs. These researchers found that although a higher ATG dose was associated with better GVHD prevention, it increased the risk of infectious complications, which was similarly observed in the results of the current analysis (Supplementary Table 2); however, Chang et al. [5] only included standard-risk disease and used myeloablative conditioning. A recent Korean study also suggested that ATG doses ranging from 2.5 to $7.5 \mathrm{mg} / \mathrm{kg}$ were associated with better survival in comparison to doses ranging from 9 to $12 \mathrm{mg} / \mathrm{kg}$ in recipients of mismatched HCT for acute leukemia or MDS [6].

Interestingly, in the present study, the survival benefit of the $6 \mathrm{mg} / \mathrm{kg}$ ATG dose over the $9 \mathrm{mg} / \mathrm{kg}$ dose was apparent only in patients with low or intermediate DRI, but not in those with high or very high DRI. Indeed, RIC HCTs for hematologic malignancies are expected to exert its main therapeutic effects through graft-versus-leukemia (GVL) effects, and a close association between chronic GVHD and GVL has been noted previously [7, 8]. Because patients with high or very high DRI are at a higher risk of relapse than those with low or intermediate DRI, an ATG dose of $6 \mathrm{mg} / \mathrm{kg}$ may have been excessive for them.

Our study has several limitations. First, the retrospective nature of this study may render this analysis hypothesis-generating at most. Second, this study did not address the interaction between ATG dose and donor types. Although donor type was not significantly associated with survival in the multivariable analysis, subtle differences may have not been detected due to the limited number of patients included in the study.

In conclusion, the present study suggests that a total ATG dose of $6 \mathrm{mg} / \mathrm{kg}$ is more suitable than that of $9 \mathrm{mg} / \mathrm{kg}$ in RIC PB HCT from alternative donors in patients with acute leukemia or MDS and low or intermediate DRI, while those with high or very high DRI may require a more cautious strategy on GVHD prophylaxis.

\section{Mihong Choi ${ }^{1}$, Dong-Yeop Shin ${ }^{1,2,3}$, Ji Yun Lee ${ }^{4}$, Inho Kim ${ }^{1,3}$, Sung-Soo Yoon ${ }^{1,2,3}$, Soo-Mee Bang ${ }^{4}$ ${ }^{1}$ Department of Internal Medicine, ${ }^{2}$ Center for Medical Innovation, Biomedical Research Institute, Seoul National University Hospital, ${ }^{3}$ Cancer Research Institute, Seoul National University College of Medicine, Seoul, \\ ${ }^{4}$ Department of Internal Medicine, Seoul National University Bundang Hospital, Seongnam, Korea \\ Correspondence to: Dong-Yeop Shin Department of Internal Medicine, Seoul National University Hospital, 101 Daehak-ro, Jongno-gu, Seoul 03080, Korea E-mail: stephano.dyshin@gmail.com}

Received on Jul. 30, 2019; Revised on Aug. 16, 2019; Accepted on Aug. 22, 2019 https://doi.org/10.5045/br.2019.54.4.290

\section{ACKNOWLEDGMENTS}

This study was supported a grant by the National from Research Foundation of Korea (NRF) Grant funded by the Korean Government (MSIP) (No. NRF-2016R1A5A1011974).

\section{Authors' Disclosures of Potential Conflicts of Interest}

No potential conflicts of interest relevant to this article were reported.

\section{REFERENCES}

1. Arai S, Arora M, Wang T, et al. Increasing incidence of chronic graft-versus-host disease in allogeneic transplantation: a report from the Center for International Blood and Marrow Transplant Research. Biol Blood Marrow Transplant 2015;21:266-74.

2. Baron F, Mohty M, Blaise D, et al. Anti-thymocyte globulin as graft-versus-host disease prevention in the setting of allogeneic peripheral blood stem cell transplantation: a review from the Acute Leukemia Working Party of the European Society for Blood and Marrow Transplantation. Haematologica 2017;102: 224-34.

3. Kumar A, Reljic T, Hamadani M, Mohty M, Kharfan-Dabaja MA. Antithymocyte globulin for graft-versus-host disease prophylaxis: an updated systematic review and meta-analysis. Bone Marrow Transplant 2019;54:1094-106.

4. Remberger M, Ringden O, Hägglund $\mathrm{H}$, et al. A high antithymocyte globulin dose increases the risk of relapse after reduced intensity conditioning HSCT with unrelated donors. Clin Transplant 2013;27:E368-74.

5. Chang YJ, Wang Y, Mo XD, et al. Optimal dose of rabbit thymoglobulin in conditioning regimens for unmanipulated, haploidentical, hematopoietic stem cell transplantation: Long-term outcomes of a prospective randomized trial. Cancer 2017; 123:2881-92.

6. Kim T, Choi Y, Lee JH, et al. Clinical impact of anti-thymocyte globulin on survival and graft-versus-host disease in patients undergoing human leukocyte antigen mismatched allogeneic stem cell transplantation. Korean J Intern Med 2019. [Epub ahead of print]

7. Valcarcel D, Martino R, Caballero D, et al. Sustained remissions of high-risk acute myeloid leukemia and myelodysplastic syndrome after reduced-intensity conditioning allogeneic hematopoietic transplantation: chronic graft-versus-host disease is the strongest factor improving survival. J Clin Oncol 2008; 26:577-84.

8. Thepot S, Zhou J, Perrot A, et al. The graft-versus-leukemia effect is mainly restricted to NIH-defined chronic graft-versus-host disease after reduced intensity conditioning before allogeneic stem cell transplantation. Leukemia 2010;24:1852-8. 


\section{Supplementary Methods}

\section{Definition}

Acute graft-versus-host disease (GVHD) was diagnosed and graded clinically according to the Glucksberg's criteria [1], and chronic GVHD according to the National Institutes of Health Consensus criteria [2]. Relapse was defined by any evidence of the disease after the hematopoietic cell transplantation (HCT), and non-relapse mortality (NRM) was defined as death from any cause except for relapse. The HCT comorbidity index (HCT-CI) was applied according to a previous study by Sorror et al. [3] The disease risk index (DRI) consisted of the disease and stage risk, each of which was derived from a diagnosis with the cytogenetics data and remission status at the time of the HCT, respectively, and has been shown to successfully risk stratify heterogenous allogeneic transplant recipients [4]. For the current study, the DRI was collapsed into a 2-group system of low/intermediate and high/very high risk, as proposed by the original study [4].

Statistical endpoints included GVHD-free, relapse-free survival (GRFS), disease-free survival (DFS), and overall survival (OS). GRFS is a composite endpoint encompassing ongoing morbidity from GVHD in addition to relapse and death $[5,6]$. GRFS events were defined as grade III-IV acute GVHD, chronic GVHD requiring systemic immunosuppressive treatment, relapse, or death. DFS was calculated as the time from the HCT to relapse or death, and OS was defined as the time from the HCT to death.

\section{Statistical methods}

Patient and treatment characteristics were compared with Chi-square test for categorical variables and t-test for continuous variables. Survival curves were plotted using the

Supplementary Table 1. Patients and treatment characteristics.

\begin{tabular}{|c|c|c|c|c|}
\hline \multirow{2}{*}{ Variables } & \multirow{2}{*}{$\begin{array}{c}\text { Overall } \\
(\mathrm{N}=130)\end{array}$} & \multicolumn{2}{|c|}{ By ATG doses } & \multirow{2}{*}{$P^{\text {a) }}$} \\
\hline & & $6 \mathrm{mg} / \mathrm{kg}(\mathrm{N}=43)$ & $9 \mathrm{mg} / \mathrm{kg}(\mathrm{N}=87)$ & \\
\hline Patient age, median (range) & $52(16-68)$ & $55(18-67)$ & $52(16-68)$ & 0.219 \\
\hline Patient sex, $\mathrm{N}(\%)$ & & & & 0.264 \\
\hline Male & $68(52.3 \%)$ & $19(44.2 \%)$ & $49(56.3 \%)$ & \\
\hline Female & $62(47.7 \%)$ & $24(55.8 \%)$ & $38(43.7 \%)$ & \\
\hline HCT-Cl total scores, median (range) & $0(0-5)$ & $0(0-4)$ & $0(0-5)$ & 0.411 \\
\hline Disease, N (\%) & & & & 0.073 \\
\hline $\mathrm{AML}$ & $78(60.0 \%)$ & $28(65.1 \%)$ & $50(57.5 \%)$ & \\
\hline MDS & $19(14.6 \%)$ & $2(4.7 \%)$ & $17(19.5 \%)$ & \\
\hline ALL & $33(25.4 \%)$ & $13(30.2 \%)$ & $20(23.0 \%)$ & \\
\hline Disease risk index & & & & 1.000 \\
\hline Low/intermediate & 99 (76.2\%) & $33(76.7 \%)$ & $66(75.9 \%)$ & \\
\hline High/very high & $31(23.8 \%)$ & $10(23.3 \%)$ & $21(24.1 \%)$ & \\
\hline Time from diagnosis to HCT in mo, median (range) & $5.92(2.07-197.43)$ & $5.46(2.07-31.50)$ & $6.07(2.57-197.43)$ & 0.450 \\
\hline Female donor-to-male patient, N (\%) & $21(16.2 \%)$ & $5(11.6 \%)$ & $16(18.4 \%)$ & 0.464 \\
\hline Donor type & & & & 0.008 \\
\hline HID & $55(42.3 \%)$ & $25(58.1 \%)$ & $30(34.5 \%)$ & \\
\hline PUD & $31(23.8 \%)$ & $4(9.3 \%)$ & $27(31.0 \%)$ & \\
\hline MUD & $44(33.8 \%)$ & $14(32.6 \%)$ & $30(34.5 \%)$ & \\
\hline ABO incompatibility & & & & 0.592 \\
\hline Matched & $48(36.9 \%)$ & $16(37.2 \%)$ & $32(36.8 \%)$ & \\
\hline Major mismatch & $36(27.7 \%)$ & $9(20.9 \%)$ & $27(31.0 \%)$ & \\
\hline Minor mismatch & $27(20.8 \%)$ & $10(23.3 \%)$ & $17(19.5 \%)$ & \\
\hline Bidirectional & $18(13.8 \%)$ & $8(18.6 \%)$ & $10(11.5 \%)$ & \\
\hline Infused CD $34^{+}$cells in $\times 10^{6} / \mathrm{kg}$, median (range) & $5.14(0.97-12.68)$ & $5.59(1.80-12.68)$ & $4.97(0.97-12.09)$ & 0.093 \\
\hline $\mathrm{CNI}$ use & & & & $<0.001$ \\
\hline Cyclosporin A & $68(52.3 \%)$ & $12(27.9 \%)$ & $56(64.4 \%)$ & \\
\hline Tacrolimus & $52(40.0 \%)$ & $30(69.8 \%)$ & $22(25.3 \%)$ & \\
\hline Switch & $10(7.7 \%)$ & $1(2.3 \%)$ & $9(10.3 \%)$ & \\
\hline Methotrexate use & & & & 0.005 \\
\hline Yes & $79(60.8 \%)$ & $34(79.1 \%)$ & $45(51.7 \%)$ & \\
\hline No & $51(39.2 \%)$ & $9(20.9 \%)$ & $42(48.3 \%)$ & \\
\hline
\end{tabular}

${ }^{\text {a) }} P$-value by $\chi^{2}$ test for categorical variables and t-test for continuous variables.

Abbreviations: ALL, acute lymphoblastic leukemia; AML, acute myeloid leukemia; ATG, antithymocyte globulin; CNI, calcineurin inhibitor; $\mathrm{HCT}$, hematopoietic cell transplantation; $\mathrm{HCT}-\mathrm{Cl}$, hematopoietic cell transplantation comorbidity index; HID, haploidentical familial donors; MDS, myelodysplastic syndrome; MUD, matched unrelated donors; PUD, partially-matched unrelated donors. 
Supplementary Table 2. Cumulative incidence of individual failure events and crude incidence of infectious complications.

\begin{tabular}{lccc}
\hline & ATG 6 mg/kg (N=43) & ATG 9 mg/kg (N=87) & $P$ \\
\hline 100-day acute graft-versus-host disease, grade III-IV & $23.3 \%$ & $16.1 \%$ & $0.023^{\mathrm{a})}$ \\
2-year chronic graft-versus-host disease requiring systemic treatment & $41.2 \%$ & $21.0 \%$ & $0.025^{\mathrm{a})}$ \\
2-year non-relapse mortality & $16.6 \%$ & $24.3 \%$ & $0.517^{\mathrm{a})}$ \\
2-year relapse & $28.8 \%$ & $33.7 \%$ & $0.311^{\mathrm{a})}$ \\
Fungal infection & $2.3 \%$ & $25.3 \%$ & $0.003^{\mathrm{b})}$ \\
CMV infection & 0 & $3.4 \%$ & $0.541^{\mathrm{b})}$ \\
\hline
\end{tabular}

${ }^{\text {a) }} P$-value by Gray test. ${ }^{\text {b) }} P$-value by $\chi^{2}$ test.

Abbreviations: ATG, antithymocyte globulin; CMV, cytomegalovirus.

Kaplan-Meier method, and compared with the log-rank test. Cumulative incidence was estimated for individual failure events and compared using the Gray test, with death without GVHD being a competing risk for GVHD, relapse for NRM, and NRM for relapse. Cox proportional hazards models were applied to identify risk factors significantly related to survival, in which variables with statistical significance from the univariate analyses were subsequently used to construct multivariate analyses, along with the donor types. All $P$ values were 2 -sided and values of $<0.05$ were considered statistically significant. The analyses were done with two statistical software packages: SPSS version 23.0 (IBM Corp, Armonk, NY, USA) and R 3.5.1.

\section{Supplementary Results}

\section{Baseline characteristics}

The characteristics of the included 130 patients are shown in Supplementary Table 1. Overall, the median recipient age was 52 years (range, 16-68 yr) and $52.3 \%$ of the patients were males. Median HCT-CI scores were 0 both in the overall and in each of the two groups. The most common diagnosis was acute myeloid leukemia (AML, 60.0\%), followed by acute lymphoblastic leukemia (ALL, 25.4\%), and myelodysplastic syndrome (MDS, $14.6 \%$ ). The DRI was low/intermediate in $76.2 \%$ and high/very high in $23.8 \%$ of the patients. Patients received a HCT after a median of 5.92 months (range, 2.07-197.43 mo) from their diagnosis of hematologic malignancy, and about $16.2 \%$ of the cases consisted of the combination of a male recipient and a female donor. The median dose of the infused CD $34^{+}$cells was $5.14 \times 10^{6} / \mathrm{kg}$ (range, $0.97-12.68 \times 10^{6} / \mathrm{kg}$ ). Although these characteristics were generally comparable among the groups with different anti-thymocyte globulin (ATG) doses, haploidentical familial donors (HIDs) were more common in the $6 \mathrm{mg} / \mathrm{kg}$ group than in the $9 \mathrm{mg} / \mathrm{kg}$ groups, with $58.1 \%$ vs. $34.5 \%$, respectively $(P=0.008)$. In addition, tacrolimus or methotrexate was more frequently used in the $6 \mathrm{mg} / \mathrm{kg}$ group than in the $9 \mathrm{mg} / \mathrm{kg}$ groups, with $64.4 \%$ vs. $27.9 \%$ for tacrolimus $(P<0.001)$ and $79.1 \%$ vs. $51.7 \%(P=0.005)$ for methotrexate, respectively.

\section{Incidence of infectious complications}

Both fungal infection and cytomegalovirus infection were less frequently observed with a total ATG dose of $6 \mathrm{mg} / \mathrm{kg}$ compared to $9 \mathrm{mg} / \mathrm{kg}$, with a crude incidence of $2 \%$ vs. $25 \% \quad(P=0.003)$ and 0 vs. $3 \% \quad(P=0.541)$, respectively (Supplementary Table 2).

\section{References}

1. Glucksberg H, Storb R, Fefer A, et al. Clinical manifestations of graft-versus-host disease in human recipients of marrow from HL-A-matched sibling donors. Transplantation 1974;18:295-304.

2. Filipovich AH, Weisdorf D, Pavletic S, et al. National Institutes of Health consensus development project on criteria for clinical trials in chronic graft-versus-host disease: I. Diagnosis and Staging Working Group report. Biol Blood Marrow Transplant 2005;11:945-56.

3. Sorror ML, Maris MB, Storb R, et al. Hematopoietic cell transplantation (HCT)-specific comorbidity index: a new tool for risk assessment before allogeneic HCT. Blood 2005;106:2912-9.

4. Armand P, Kim HT, Logan BR, et al. Validation and refinement of the Disease Risk Index for allogeneic stem cell transplantation. Blood 2014;123:3664-71.

5. Holtan SG, DeFor TE, Lazaryan A, et al. Composite end point of graft-versus-host disease-free, relapse-free survival after allogeneic hematopoietic cell transplantation. Blood 2015;125:1333-8.

6. Solh M, Zhang X, Connor K, et al. Factors predicting graft-versus-host disease-free, relapse-free survival after allogeneic hematopoietic cell transplantation: multivariable analysis from a single center. Biol Blood Marrow Transplant 2016;22:1403-9. 